\title{
Prevalence and Direct Economic Losses from Bovine Tuberculosis in Makurdi, Nigeria
}

\author{
E. F. Ejeh, ${ }^{1,2}$ M. A. Raji, ${ }^{2}$ M. Bello, ${ }^{3}$ F. A. Lawan, ${ }^{1}$ \\ M. I. Francis, ${ }^{2}$ A. C. Kudi, ${ }^{4}$ and S. I. B. Cadmus ${ }^{5}$ \\ ${ }^{1}$ Department of Veterinary Microbiology and Parasitology, Faculty of Veterinary Medicine, University of Maiduguri, \\ PMB 1069, Maiduguri, Borno State, Nigeria \\ ${ }^{2}$ Department of Veterinary Microbiology, Faculty of Veterinary Medicine, Ahmadu Bello University, PMB 1096, Zaria, Nigeria \\ ${ }^{3}$ Department of Veterinary Public Health and Preventive Medicine, Ahmadu Bello University, PMB 1096, Zaria, Nigeria \\ ${ }^{4}$ Department of Veterinary Medicine, Ahmadu Bello University, PMB 1096, Zaria, Nigeria \\ ${ }^{5}$ Department of Veterinary Public Health and Preventive Medicine, University of Ibadan, PMB 001, Ibadan, Nigeria
}

Correspondence should be addressed to E. F. Ejeh; enenchefrancis@yahoo.com

Received 5 February 2014; Revised 25 April 2014; Accepted 28 April 2014; Published 2 June 2014

Academic Editor: Francesca Mancianti

Copyright (C) 2014 E. F. Ejeh et al. This is an open access article distributed under the Creative Commons Attribution License, which permits unrestricted use, distribution, and reproduction in any medium, provided the original work is properly cited.

\begin{abstract}
A retrospective study was conducted to investigate the prevalence of bovine tuberculosis and direct economic losses (DEL) from tuberculosis in cattle slaughtered in Makurdi abattoirs from 2008 to 2012, using abattoir records obtained from the Ministry of Agriculture and Natural Resources. Out of 61654 cattle slaughtered during the study period 1172 (1.90\%) were positive for tuberculosis lesions. The annual prevalence of bovine tuberculosis ranges from $0.90 \%$ in 2008 to $4.04 \%$ in 2012 . There was significant $(P<0.05)$ difference in annual prevalence of bovine tuberculosis. It was also observed that there was no seasonal difference in the prevalence of bovine tuberculosis. A total of 1935 affected organs by BTB weighing $3046.50 \mathrm{~kg}$, amounting to $2.91 \times 10^{6} \mathrm{Naira}(1.82 \times$ $10^{4}$ USD), were condemned within the study period. Seasonal variation in organ condemnation due to bovine tuberculosis was significantly different (Mann-Whitney $U$ statistics $=774 \times 10^{3}, P=0.034$ ). It was concluded that bovine tuberculosis is prevalent in Makurdi and accounts for heavy economic losses due to condemnation of edible organs.
\end{abstract}

\section{Introduction}

Bovine tuberculosis is a chronic bacterial disease of cattle characterized by respiratory signs [1] and production of progressive granulomatous lesion affecting thoracic and abdominal organs [2]. The disease is caused by Mycobacterium bovis, an acid fast bacilli belonging to the family Mycobacteriaceae and genus Mycobacterium [3].

Cattle serve as the primary host of Mycobacterium bovis, and disease caused by the organism has been reported in man and wild animals in Nigeria and other parts of the world where they serve as reservoir for cattle [4].

Malnutrition and stress are important predisposing factors in the pathogenesis of tuberculosis infection in cattle, and these factors are directly related to season in Africa because cattle rearing in most African countries is predominantly nomadic system and depends mainly on natural pasture [5].
Prevalence of bovine tuberculosis in Nigeria ranges from $0.5 \%$ in Oyo (southwestern state) with very low livestock population [6] to $12.27 \%$ in Gombe (northeastern state) where livestock populations are concentrated $[6,7]$.

Bovine tuberculosis is a disease of zoonotic and economic significance worldwide especially in developing countries resulting in losses of human live, productive time on the part of farmers, and huge sum of money from condemnation of carcasses at slaughter [8]. The disease is common in subSaharan Africa including Nigeria and heavy economic losses can occur in cattle and buffaloes from low productivity mortality and trade restrictions [8].

Diagnosis of tuberculosis in cattle is mainly through tuberculin testing, culture, and molecular genotyping $[9,10]$. Culture is the gold standard, however, in resource poor countries like Nigeria, monitoring of BTB by bacteriological study is not feasible because assays are costly and time consuming, 
and laboratories are ill equipped. Hence, routine diagnosis of tuberculosis at the abattoir is based on identification of characteristic tuberculosis lesions [7, 11]. Although results from abattoir meat inspection are limited in the information they provide and are prone to inspector subjectivities and errors [12]. However, meat inspection provides useful insight into the prevalence of bovine tuberculosis in Nigeria [11] and plays important role in both quality assurance and control [12]. Abattoir meat inspection also provides improvement in animal and human health with regard to consumer protection and eradication of zoonotic and epizootic tuberculosis.

Eradication of zoonotic tuberculosis in developed countries was achieved partly through abattoir meat inspection and condemnation of affected carcass or organs [13]. Hence, in the light of increasing prevalence of debilitating diseases such as HIV/AIDS and cancer in sub-Saharan Africa, abattoir meat inspection remains an appropriate tool for tuberculosis surveillance and control.

Bovine tuberculosis was first reported in Nigeria by Manley [14]; since then a lot of information on bovine tuberculosis had been reported [7, 8, 15-19], but no information on the economic losses due to condemnation of meat resulting from detection of tuberculosis lesions has been reported. Furthermore, there is no active national bovine tuberculosis surveillance and control at herd level and farms in Nigeria [20]. There is also paucity of information on the prevalence of bovine tuberculosis in Makurdi, Benue State. The aim of this study was to report the prevalence of tuberculosis lesions to determine the economic losses due to condemnation of meat resulting from detection of tuberculosis lesions in organs/tissues of slaughtered cattle in Makurdi, Benue State, from 2008 to 2012.

\section{Material and Methods}

2.1. Study Area. Makurdi is located in the north central Nigeria; it lies between latitude $7^{0} 44^{1} \mathrm{~N}$ and longitude $8^{0} 54^{1} \mathrm{E}$. Makurdi is the administrative headquarter of Benue State. It is characterised by a tropical climate, dry and wet climate; dry season lasts for a minimum of six months, beginning from November to April, while the wet season spans from May to October. Mean annual rainfall is about 1,290 mm [21]. Makurdi is located in the Benue valley and is drained by the river Benue and its tributaries. Due to the general low relief of Makurdi, a large portion of the area is waterlogged and flooded during heavy rainstorm [22]. Natural pasture is available in Makurdi throughout the year.

Cattle rearing in Nigeria is predominantly nomadic system, where Fulani herdsmen travel on foot for a very long distance for grazing purpose [6]. During the dry season, Fulani herdsmen from the extreme northeastern states and northwestern states travel over a thousand kilometre to Benue valley where pasture is available throughout the year for grazing [6].

Makurdi has two abattoirs that supply slaughtered meat for over 500,000 people; an average of 80 heads of cattle are slaughtered daily. Cattle slaughtered in Makurdi originate from Benue State and from cattle markets in close by states such as Nasarawa, Niger, Taraba, Adamawa, Bauchi, and
Plateau State. Most of the cattle slaughtered in the abattoirs were adult local breeds.

2.2. Collection of Data. Abattoir records for a period of five years (2008-2012) were collated from the Ministry of Agriculture and Natural Resources, Makurdi, Benue State. From abattoir records, data on tuberculosis cases per month were extracted. These include the number of cattle examined before slaughter and the number and types of whole edible organs condemned as a result of the presence of tuberculosis lesions. Partially condemned edible organs were not included in the study because their actual or estimated quantity was not recorded. There was no record for whole carcass condemnation from detection of tuberculosis lesions. It was not possible to get the correct data on age, breed, and sex for each of the slaughtered cattle during the study period due to poor abattoir recording system at the Ministry of Agriculture and Natural Resources (MANR), Makurdi. Veterinarians who are staff of the Ministry of Agriculture and Natural Resources (MANR), Makurdi, carried out postmortem examination.

\subsection{Estimation of Financial Losses Resulting from Condem-} nation of Meat Suspected of Tuberculosis. The average cost per kilogram of edible organs was obtained through oral interviews with the butchers and meat traders at the abattoirs. The average costs of organs like lungs and spleen, which are sold without weighing, were also obtained through oral interviews with butchers and meat traders. The total numbers of livers, lungs, hearts, spleens, and other organs that are condemned as unfit for human consumption during meat inspection were noted for cattle slaughtered in Makurdi abattoirs for a period of five years.

Financial losses in Naira and Dollar were subsequently calculated based on the basis of a previous pilot study [23] and the formula DEL $=n W \times A v \cdot P / \mathrm{kg}$ was used to determine financial losses.

And DEL stands for direct economic losses due to total meat condemned, $n$ is the total number of condemned organs for the period, $W$ is the total weight of condemned organs, and $\mathrm{Av} \cdot \mathrm{P} / \mathrm{Kg}$ is the average price of whole normal or passed organ/kilogram.

2.4. Data Analysis. From the data obtained, the annual, seasonal, monthly, and overall prevalence of BTB were calculated as the total number of cases of BTB detected divided by the total number of cattle slaughtered at particular point in time.

Data obtained were further subjected to Mann-Whitney statistics and ANOVA for the establishment of significance using SPSS statistic software version 16.

\section{Results}

3.1. Annual and Seasonal Prevalence. Table 1 showed the annual and seasonal distribution of the prevalence of bovine tuberculosis (BTB) from 2008 to 2012. An overall detection rate of $1.90 \%$ (1.45-3.05) was recorded for a period of five years (Table 1). In 2008, 1942 (37.51\%) cattle were slaughtered with a lower prevalence of $0.90 \%(0.65-1.18 \%)$, while, in 2012, 
TABLE 1: Annual prevalence of tuberculosis lesions in cattle slaughtered in Makurdi abattoirs from 2008 to 2012.

\begin{tabular}{ccccc}
\hline Parameter & $\begin{array}{c}\text { Number of } \\
\text { slaughtered } \\
\text { cattle }(\%)\end{array}$ & $\begin{array}{c}\text { Number } \\
\text { of TB } \\
\text { lesions }\end{array}$ & $\begin{array}{c}\text { Prevalence } \\
(\%)\end{array}$ & $95 \%$ CI \\
\hline Year & & & & \\
2008 & $19429(31.51)$ & 175 & $0.90^{\mathrm{a}}$ & $(0.65-1.18)$ \\
2009 & $17011(27.60)$ & 341 & $2.00^{\mathrm{a}}$ & $(1.19-2.64)$ \\
2010 & $10988(17.82)$ & 265 & 2.41 & $(1.67-3.32)$ \\
2011 & $10104(16.39)$ & 230 & 2.28 & $(0.94-3.70)$ \\
2012 & $4131(6.70)$ & 167 & $4.04^{\mathrm{b}}$ & $(-3.17-13.13)$ \\
Season & & & & \\
Raining & $37262(60.44)$ & 631 & 1.69 & $(-2.63-0.59)$ \\
Dry & $24392(39.56)$ & 547 & 2.24 & $(-2.86-0.82)$ \\
\hline Total & 61654 & 1172 & 1.90 & $(1.45-3.05)$ \\
\hline
\end{tabular}

Mean percentages with the different letters in the same column were significantly different $(P>0.05)$.

data collected for a period of six (6) months showed a higher prevalence of $4.04 \%(-3.17-13.13)$. Annual prevalence rate of bovine tuberculosis ranges from $0.90 \%$ in 2008 to $4.04 \%$ in 2012. There was significant $(P<0.05)$ difference between the prevalence of bovine tuberculosis recorded in 2012 and that in $2008,2009$.

3.2. Seasonal Variation. 61654 cattle were slaughtered in the two Makurdi abattoirs from 2008 to 2012 with 37262 (60.40\%) cattle being slaughtered during rainy season. Prevalence of $1.69 \%$ of bovine tuberculosis was recorded. Lower figures (24392) were slaughtered during the dry season with prevalence of $2.24 \%$ BTB. There was no statistically significant $(P>$ 0.05 ) difference between the rainy and dry seasons (MannWhitney $U$ statistics $=267.50, P=0.12$ ).

3.3. Direct Economic Loss (DEL). Table 2 showed the financial (direct economic) losses and number and weight of edible cattle organs condemned on annual basis for a five-year period (2008-2012). 1935 (3046.50 kg) edible organs valued at $\mathrm{N} 2.91 \times 10^{6}\left(\$ 1.82 \times 10^{4}\right)$ were condemned. In 2009, 675 $(34.89 \%)$ organs weighing $1070 \mathrm{~kg}$ and valued at N1.00 $\times 10^{6}$ (\$6293.14) were also condemned, while in 2012236 organs (12.20\%) weighing $363.00 \mathrm{~kg}$ and worth $\mathrm{N} 3.56 \times 10^{5}$ (\$2231.26) were similarly destroyed.

There was no significant $(P>0.05)$ difference between direct economic loss in edible organs condemned in 2009 and 2012. However, there was significant difference between the direct economic losses in 2008, 2009, 2010, and $2011(P<$ $0.05)$.

3.4. Seasonal Economic Losses. Table 2 also showed the seasonal economic loss resulting from condemnation of edible organs from cattle suspected of tuberculosis in Makurdi abattoirs. $784(40.52 \%)$ organs, weighing $1249.00 \mathrm{~kg}$ and valued at $\mathrm{N} 1.19 \times 10^{6}(\$ 7483.80)$, were condemned during the rainy season. During the dry season, 1151 (59.48\%) organs,

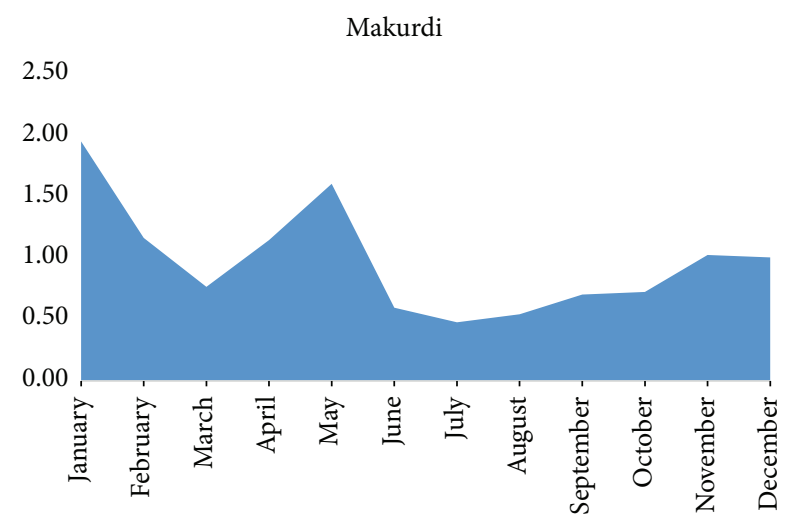

FIGURE 1: Monthly average prevalence of tuberculosis lesions in cattle slaughtered in Makurdi from 2008 to 2012.

weighing $1797.50 \mathrm{~kg}$ and valued at N1.72 $\times 10^{6}\left(\$ 1.07 \times 10^{4}\right)$, were condemned. There was a statistically significant $(P<$ 0.05) difference between edible organs condemned during the dry and rainy seasons (Mann-Whitney $U$ statistics = $\left.7.74 \times 10^{3}, P=0.034\right)$.

3.5. Economic Losses from Different Organs. During the study period, 912 (47.13\%) lungs were condemned; this figure was valued at $\mathrm{N} 9.12 \times 10^{5}(\$ 5700.00)$; the number of spleens condemned was $219(11.32 \%)$, valued at N8.30 $\times 10^{4}(\$ 547.50)$. lungs and spleen were sold at N1000 (\$6.25) and N350 (\$2.50) per organ without weighing.

A total of $523(27.03 \%)$ livers, weighing $1569.00 \mathrm{~kg}$ and valued at N1.57 $\times 10^{6}(\$ 9806.25)$, were condemned, while $176(9.06 \%)$ hearts, weighing $262.50 \mathrm{~kg}$ valued at N1.62 $\times 10^{5}$ (\$1640.73) and 105 (5.43\%) kidneys, weighing $84.00 \mathrm{~kg}$ and valued at $\mathrm{N} 8.47 \times 10^{4}(\$ 525.00)$ were condemned.

There was a significant difference between the direct economic losses among edible organs condemned as result of tuberculosis lesions.

Statistical analysis showed that there was significant difference between direct economic losses (DEL) from condemnation of edible organs due to bovine tuberculosis during the raining season and dry season (Mann-Whitney $U$ statistics = $7.745 \times 10^{3}, P=0.034$ ).

Figure 1 shows the magnitude of change in the relationship between the bovine tuberculosis cases over a period of five years based on their average monthly prevalence; the prevalence rate was highest in January; it decreases sharply in February to March and then increases in April and decreases from May to June drastically. The decrease was maintained relatively but gradually increased from September to December.

\section{Discussions}

Abattoir meat inspection through macroscopic examination of tuberculosis lesion is important in the context of tuberculosis surveillance and disease monitoring [24]. Results from abattoir based investigation have provided useful information on bovine tuberculosis over the years in Africa $[7,25,26]$. 
TABLE 2: Direct economic loss from condemnation of edible organs as a result of detection of tubercle lesion in cattle slaughtered in Makurdi abattoirs.

\begin{tabular}{|c|c|c|c|c|}
\hline \multirow{2}{*}{ Parameters } & \multirow{2}{*}{ Number of condemned cattle $(n)(\%)$} & \multirow{2}{*}{ Weight $(W)(\mathrm{Kg})$} & \multicolumn{2}{|c|}{$\mathrm{DEL}^{* *}$} \\
\hline & & & $(\mathrm{N})$ & $(\$)$ \\
\hline \multicolumn{5}{|l|}{ Year } \\
\hline 2008 & $322(16.64)$ & 517.30 & $5.01 \times 10^{5}$ & 3101.90 \\
\hline 2009 & $675(34.89)$ & 1070.50 & $1.00 \times 10^{6}$ & 6293.14 \\
\hline 2010 & $358(18.50)$ & 554.50 & $5.34 \times 10^{5}$ & 3345.65 \\
\hline 2011 & $344(17.78)$ & 541.20 & $5.18 \times 10^{5}$ & 3247.53 \\
\hline 2012 & $236(12.20)$ & 363.00 & $3.56 \times 10^{5}$ & 2231.26 \\
\hline \multicolumn{5}{|l|}{ Organs } \\
\hline Lungs* & $912(47.13)$ & $912.00^{*}$ & $9.12 \times 10^{5 \mathrm{a}}$ & 5700.00 \\
\hline Liver & $523(27.03)$ & 1569.00 & $1.57 \times 10^{6 \mathrm{~b}}$ & 9806.25 \\
\hline Heart & $176(9.20)$ & 262.50 & $1.62 \times 10^{5 c}$ & 1640.73 \\
\hline Spleen* ${ }^{*}$ & $219(11.32)$ & $219.00^{*}$ & $8.30 \times 10^{4 \mathrm{c}}$ & 547.50 \\
\hline Kidney & $105(5.43)$ & 84.00 & $8.47 \times 10^{4 c}$ & 525.00 \\
\hline \multicolumn{5}{|l|}{ Seasons } \\
\hline Raining & $784(40.52)$ & 1249.00 & $1.19 \times 10^{6 \mathrm{~d}}$ & 7483.80 \\
\hline Dry & 1151 (59.48) & 1797.50 & $1.72 \times 10^{6 e}$ & $1.07 \times 10^{4}$ \\
\hline Total & $1935(100)$ & 3046.50 & $2.91 \times 10^{6}$ & $1.82 \times 10^{4}$ \\
\hline
\end{tabular}

However, not a novel finding per se, in developing countries where laboratories are ill equipped and with endemic bovine tuberculosis, postmortem diagnosis by detection of macroscopic lesions remains the best option $[7,26]$.

Detection rate of gross pathological lesions of bovine tuberculosis (BTB) was high (4.04\%) in 2012; there was a gradual increase in the prevalence of BTB from 2008 to 2012. This pattern seems to disagree with the result of Opara [27] who observed that there was a decrease in the prevalence of bovine tuberculosis (BTB) along three years (1999 to 2002). He further explained that the decrease could result from recent public awareness campaign about tuberculosis and better meat inspection. This explanation may be different from the situation in Makurdi, where information on bovine tuberculosis was scarce and meat inspection at abattoirs was less thorough. Similar pattern was reported in Maiduguri [11]. Other studies in Nigeria do not follow a particular pattern [7]. In Cameron, Awah Ndukum et al., [5] reported a fluctuation in annual prevalence of BTB; they further explained that the reason for the fluctuation was not clear and emphasized that inadequacies in capacity and lack of thoroughness of veterinary staff carrying out meat inspection could have played major role.

Detection of BTB lesions during the rainy season was not different from the dry season. This agreed with the results of Awah Ndukum et al., [5] who further observed that BTB detection rate was high during stressful periods such as interseason and peak season periods and when slaughter was elevated during religious feasts and sociocultural ceremonies.

Ameen et al. [28] also made similar findings while Opara [27] reported differences in seasonal prevalence; he explained that Fulani herdsmen brought their cattle to the southern part of Nigeria to graze and emigrate when the rain begins in the north and that possibly these cattle may had acquired the infection from north before embarking on the southward migration for pasture.

The overall prevalence of bovine tuberculosis (BTB) form 2008 to 2012 in Makurdi was $1.90 \%$. This result was lower than previous reports of prevalence of BTB in neighbouring Nasarawa State where prevalence of $15.08 \%$ was reported among cattle population [29], in Taraba State was 2.8\% [30], and in other parts of the country such as in abattoirs in Oyo State was $4.47 \%$ [15]. Lower prevalence was reported in Ogbomosho, 0.54\% [28].

The reason for the low prevalence of tuberculosis lesions in Makurdi abattoirs was unclear but butchers' behaviour and lack of thoroughness of meat inspection officers in Benue State may play significant role.

The low prevalence reported in this study may be due to underestimation of tuberculosis in cattle due to small or microscopic lesions being missed and poor postmortem technique or meat inspectors discountenance under pressure from butchers [31].

Animals slaughtered for human consumption are subject to antemortem and postmortem veterinary inspection. The practice of postmortem inspection of slaughtered animal for human consumption differs depending on countries requirement and economic status [32].

European countries have well-developed and documented criteria for the condemnation of organs/carcase unfit for human or animal consumption. These include meat from animal in which generalized tuberculosis has been diagnosed.

The meat from animal which has produced a positive or inconclusive reaction with tuberculin and in which an 
examination been carried out has revealed only localized tuberculosis lesions in a number of organs or areas of the carcase [32].

However, as a tuberculosis lesion has been discovered in a lymph node of some organ or part of the carcase, only the affected organ or part of the carcase and the associated lymph nodes shall be declared unfit for human consumption.

However, in developing countries such as Nigeria and Ghana, criteria for condemnation of tuberculosis organ/carcase differ greatly from that of developed countries because of their peculiar economic situation.

Localized tuberculosis organ/carcase is trimmed and then passed for human consumption, while massive or generalised tuberculosis organ/carcase is declared unfit for human consumption [25].

At the time of the study, a total of 1935 edible organs, weighed $3046.50 \mathrm{Kg}$ and valued at two million nine hundred and ten thousand Naira (N2910000) (eighteen thousand two hundred US Dollar (\$18200)), were condemned as a result of detection of tuberculosis lesions in cattle during meat inspection in Makurdi abattoirs.

Condemnation of edible organs valued at a huge sum of money as reported here may explain the aggressive behaviour of butchers toward meat inspector at abattoirs in Nigeria [8] and other parts of Africa [2,33]; also butchers are not compensated for partial and whole organs or carcass condemnation; hence they bear the financial burden alone [34]. This may further explain why whole carcass condemnation is rare and trimming of affected parts was carried out, after which the remaining parts were passed for human consumption in contrast to the practice in developed countries.

Tuberculosis contributes to the economic suffering of our people; this is because some farmers and traders depend entirely on the proceeds from sales of cattle offal as their source of livelihood [34].

Condemnation of dibble organs without compensation deprives this group of people of their source of livelihood. Hence, this may contribute to increasing social vices such as the insurgency in the livestock-rich northern parts of Nigeria [6].

Edible organs condemned include lung, liver, heart, spleen, and kidney; these organs are sometimes prescribed by health officials for children, pregnant mothers, immunocompromised individuals, and people suffering from other health conditions as these are excellent sources of minerals, vitamins, amino acids, and other nutrients.

Condemnation of large quantity of organs without compensation may lead to increase in their cost price, thus depriving the economic poor in our society of access to such source of vital nutrients.

Lungs were more condemned than other organs; this agrees with the result of Rohnoczy et al., [35] who observed that gross lesions of tuberculosis were most often in the lung, and Mycobacterium are obligatory, aerobic, intracellular pathogens which have a predilection for the lung tissues rich in oxygen supply [36].

There was a significant difference in economic losses from condemned liver and other edible organs. This is because the liver is heavier than other condemned organs; it is also very expensive as its demand is very high due to its high nutrient contents.

The reason for the statistical difference in the economic losses of condemned edible organs during the raining season and dry season is not clear.

\section{Conclusions}

Tuberculosis is prevalent in cattle slaughtered for human consumption in Makurdi, and infected cattle can serve as a source of infection for the general public. Gross pathological examination of carcasses is a good method of screening meat before it is considered fit for human consumption. There is high loss in terms of protein and money resulting from bovine tuberculosis. Condemned carcasses and/or meat should be compensated adequately to encourage butchers in the fight against tuberculosis.

\section{Conflict of Interests}

All the authors declare that they have no conflict of interests regarding the publication of this paper.

\section{Acknowledgment}

The authors are grateful to the staff of the Benue State Ministry of Agriculture and Natural Resources (MANR) for their assistant and cooperation during the course of this research.

\section{References}

[1] L. M. O’Reilly and C. J. Daborn, “The epidemiology of Mycobacterium bovis infections in animals and man: a review," Tubercle and Lung Disease, vol. 76, no. 1, pp. 1-46, 1995.

[2] J. E. Shitaye, B. Getahun, T. Alemayehu et al., "A prevalence study of Bovine tuberculosis by using abattoir meat inspection and tuberculin skin testing data, histopathological and IS6110 PCR examination of tissues with tuberculous lesions in cattle in Ethiopia," Veterinarni Medicina, vol. 51, no. 11, pp. 512-522, 2006.

[3] N. H. Smith, S. V. Gordon, R. de la Rua-Domenech, R. S. Clifton-Hadley, and R. G. Hewinson, "Bottlenecks and broomsticks: the molecular evolution of Mycobacterium bovis," Nature Reviews Microbiology, vol. 4, no. 9, pp. 670-681, 2006.

[4] O. Cosivi, J. M. Grange, C. J. Daborn et al., "Zoonotic tuberculosis due to Mycobacterium bovis in developing countries," Emerging Infectious Diseases, vol. 4, no. 1, pp. 59-70, 1998.

[5] J. Awah Ndukum, A. Caleb Kudi, G. Bradley, I. N. AneAnyangwe, S. Fon-Tebug, and J. Tchoumboue, "Prevalence of Bovine tuberculosis in abattoirs of the littoral and western highland regions of cameroon: a cause for public health concern," Veterinary Medicine International, vol. 2010, Article ID 495015, 8 pages, 2010.

[6] R. Blench, Traditional LivesTock Breeds: Geographical Distribution and Dynamics in Relation to the Ecology of West Africa, Overseas Development Institute, London, UK, 1999. 
[7] M. M. Aliyu, Y. J. Adamu, and Y. A. Bilyaminu, "Current prevalence of tuberculosis lesions among slaughtered cattle in Northeastern States of Nigeria," Revue d'Elevage et de Medecine Veterinaire des Pays Tropicaux, vol. 62, no. 1, pp. 13-16, 2009.

[8] S. I. Cadmus, H. K. Adesokan, A. O. Jenkins, and D. Van Soolingen, "Mycobacterium bovis and M. tuberculosis in Goats, Nigeria," Emerging Infectious Diseases, vol. 15, no. 12, pp. 20662067, 2009.

[9] R. M. Warren, N. C. Gey van Pittius, M. Barnard et al., "Differentiation of Mycobacterium tuberculosis complex by PCR amplification of genomic regions of difference," International Journal of Tuberculosis and Lung Disease, vol. 10, no. 7, pp. 818822, 2006.

[10] R. Brosch, S. V. Gordon, M. Marmiesse et al., "A new evolutionary scenario for the Mycobacterium tuberculosis complex," Proceedings of the National Academy of Sciences of the United States of America, vol. 99, no. 6, pp. 3684-3689, 2002.

[11] I. O. Igbokwe, I. Y. Madaki, S. Danburam, J. A. Ameh, M. M. Aliyu, and C. O. Nwosu, "Prevalence of pulmonary tuberculosis lesions in cattle slaughtered in abattoirs in North-Eastern Nigeria," Revue d'Elevage et de Medecine Veterinaire des Pays Tropicaux, vol. 54, pp. 191-194, 2001.

[12] J. Awah-Ndukum, A. C. Kudi, G. Bradley et al., "Prevalence of Bovine tuberculosis in cattle in the highlands of Cameroon based on the detection of lesions in slaughtered cattle and tuberculin skin tests of live cattle," Veterinarni Medicina, vol. 57, no. 2, pp. 59-76, 2012.

[13] C. O. Thoen, J. H. Steele, and M. J. Gilsdor, Mycobacterium bovis Infection in Animals and Humans, Blackwell, 2nd edition, 2006.

[14] I. Alhaji, "Bovine tuberculosis: a general review with special reference to Nigeria," The Veterinary Bulletin, pp. 829-841, 1976.

[15] A. O. Jenkins, S. I. B. Cadmus, E. H. Venter et al., "Molecular epidemiology of human and animal tuberculosis in Ibadan, Southwestern Nigeria," Veterinary Microbiology, vol. 151, no. 1-2, pp. 139-147, 2011.

[16] S. Cadmus, S. Palmer, M. Okker et al., "Molecular analysis of human and bovine tubercle bacilli from a local setting in Nigeria," Journal of Clinical Microbiology, vol. 44, no. 1, pp. 2934, 2006.

[17] S. I. B. Cadmus, M. K. Yakubu, A. A. Magaji, A. O. Jenkins, and D. van Soolingen, "Mycobacterium bovis, but also M. africanum present in raw milk of pastoral cattle in North-Central Nigeria," Tropical Animal Health and Production, vol. 42, no. 6, pp. 10471048, 2010.

[18] A. Y. Kwaghe, J. A. Ameh, A. Ambali, J. T. Gararawa, G. Bukar, and U. Jauro, "A retrospective study on bovine and human tuberculosis cases in Maiduguri, Borno State," Researcher, vol. 3, no. 4, pp. 39-43, 2011.

[19] M. S. Damina, O. A. Owoludun, S. Chukwukere, J. A. Ameh, and M. M. Aliyu, "The use of deletion analysis in the detection of Mycobacterium bovis, Mycobacterium tuberculosis and Mycobacterium africanum among slaughtered cattle in Plateau State, North Central Nigeria," Nigerian Veterinary Journal, vol. 32, no. 1, pp. 9-15, 2011.

[20] S. I. B. Cadmus, N. N. Atsanda, S. O. Oni, and E. E. U. Akang, "Bovine tuberculosis in one cattle herd in Ibadan in Nigeria," Veterinarni Medicina, vol. 49, no. 11, pp. 406-412, 2004.

[21] A. E. Gobo, "Relationship between rainfall trends and flooding in the Niger-Benue River Basin," The Journal of Meteorology, vol. 13, no. 132, pp. 318-324, 1988.

[22] T. E. Ologunorisa and T. Tersoo, "The changing rainfall pattern and its implication for flood frequency in Makurdi, Northern
Nigeria," Journal of Applied Science and Environmental Managment, vol. 10, no. 3, pp. 97-102, 2006.

[23] A. W. Mbaya, P. Shingu, and J. Luka, "A retrospective study on the prevalence of fasciola infection in sheep and goats at slaughter and associated economic losses from condemnation of infected liver in Maidugri abattoir, Nigeria," Nigerian Veterinary Journal, vol. 31, no. 3, 2010.

[24] E. Liebana, L. Johnson, J. Gough et al., "Pathology of naturally occurring Bovine tuberculosis in England and Wales," Veterinary Journal, vol. 176, no. 3, pp. 354-360, 2008.

[25] N. A. K. Adu-Bobi, E. E. Mak-Mensah, D. G. Achel, O. K. Gyamfi, and K. D. Bedzra, "Preliminary investigation of Bovine tuberculosis in suspected beef from a metropolitan abattoir in ghana with ziehl-neelsen microscopy," Pakistan Journal of Biological Sciences, vol. 12, no. 17, pp. 1222-1225, 2009.

[26] L. A. Corner, "Post mortem diagnosis of Mycobacterium bovis infection in cattle," Veterinary Microbiology, vol. 40, no. 1-2, pp. 53-63, 1994.

[27] M. N. Opara, "Pathological conditions from abattoirs in Akwa Ibom state, Nigeria," Animal Research International, vol. 2, no. 2, pp. 314-318, 2005.

[28] S. A. Ameen, O. S. Adedeji, A. K. Raheem, O. O. Leigh, T. A. Rafiu, and A. O. Ige, "Current status of Bovine tuberculosis in Ogbomoso Area of Oyo State," Middle-East Journal of Scientific Research, vol. 3, no. 4, pp. 207-210, 2008.

[29] C. A. Yohanna, I. F. Ijabone, and S. I. B. Cadmus, "Prevalence of Bovine tuberculosis using single comparative intradermal tubeculin test (SCITT) in Fulani herds in Nasarawa State, North Central Nigeria," Sokoto Journal of Veterinary Science, vol. 7, no. 2, pp. 46-48.

[30] S. Danbirni, S. O. Okaiyeto, I. A. Joshua, K. B. Sackey, K .C. Anthony, and I. A. Abdulkadir, "Prevalence of tuberculosis in a herd of cattle of a tuberculosis herdman following trace back Information from a Hospital in Taraba State, Nigeria," Journal of Animal Production Advances, vol. 2, no. 7, pp. 325-328, 2012.

[31] I. A. Raufu and J. A. Ameh, "Prevalence of Bovine tuberculosis in Maiduguri, Nigeria-an abattoir study," Bulletin of Animal Health and Production in Africa, pp. 119-123, 2010.

[32] EFSA, "Opinion of the scientific panel on biological hazards on a request from the commission related on tuberculosis in bovine animals: risk for human health and control strategies," The EFSA Journal, vol. 13, pp. 1-52, 2003.

[33] L. Corner, L. Melville, K. McCubbin et al., "Efficiency of inspection procedures for the detection of tuberculous lesions in cattle," Australian Veterinary Journal, vol. 67, no. 11, pp. 389392, 1990.

[34] A. A. Ibironke and F. O. Fasina, "Socio-economic implications of bovine liver rejection in a major abattoir in South-Western Nigeria," Revista de Ciências Agrárias, vol. 33, no. 2, pp. 211-216, 2010.

[35] E. B. Rohonczy, A. V. Balachandran, T. W. Dukes et al., "A comparison of gross pathology, histopathology, and mycobacterial culture for the diagnosis of tuberculosis in elk (Cervus elaphus)," Canadian Journal of Veterinary Research, vol. 60, no. 2, pp. 108114, 1996.

[36] A. Raja, "Immunology of tuberculosis," Indian Journal of Medical Research, vol. 120, no. 4, pp. 213-232, 2004. 

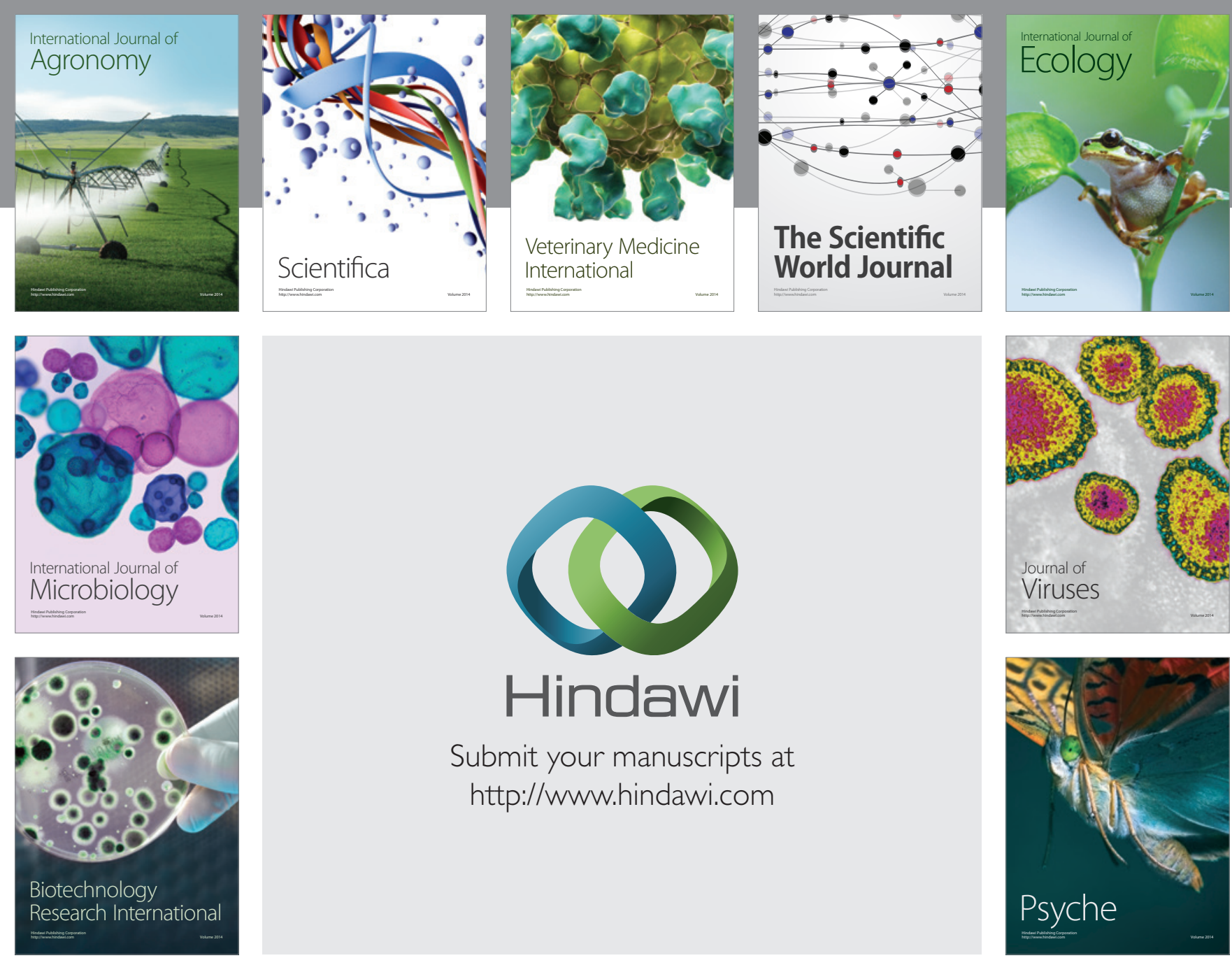

Submit your manuscripts at http://www.hindawi.com
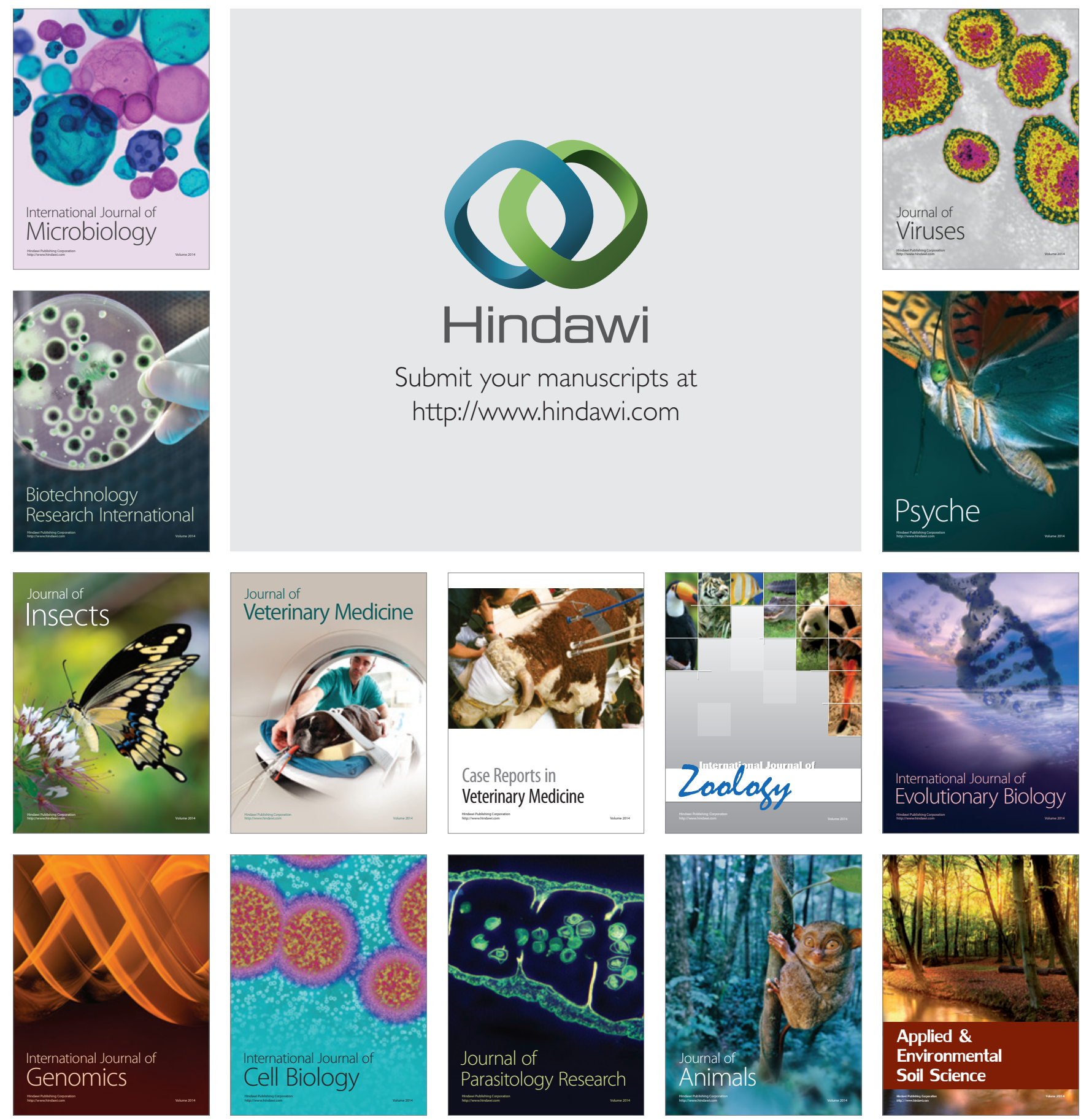